\title{
TRATAMENTO DE UM EFLUENTE DA INDÚSTRIA DO COCO EM UNIDADE PILOTO DE FLOTAÇÃO POR AR DISSOLVIDO (FAD)
}

\author{
SOUZA NETO, A. D. ${ }^{*}$, CARVALHO ${ }^{1}$, S. H. V., SOLETTI, J. I ${ }^{1}$ \\ ${ }^{1}$ Universidade Federal de Alagoas, Centro de Tecnologia \\ *e-mail: arrarife@gmail.com, jsoletti@ctec.ufal.br
}

\begin{abstract}
RESUMO
Este trabalho propõe estudar a aplicação de técnicas de sistemas de separação, mais especificamente a flotação por ar dissolvido, aplicadas ao tratamento de efluentes líquidos com contaminação de óleo e/ou sólidos em suspensão de uma indústria local de processamento de coco. A flotação por ar dissolvido é um processo consagrado em nível mundial para o tratamento de água e de efluentes industriais. A flotação é um processo pelo qual há remoção de partículas, líquidas ou sólidas, de uma fase líquida, por meio da introdução de bolhas de gás, as quais aderem à superfície dessas partículas formando aglomerados de densidade menor que a água, que ascendem à superfície, de onde serão removidas. Nesse presente trabalho foram estudados 3 tipos de coagulantes, sulfato de alumínio, sulfato de ferro e policroleto de alumínio (PAC), e um polímero aniônico. Foi observado que o poli cloreto de alumínio se destacou entre os 3 coagulantes, apresentando desempenho superior aos outros dois utilizados, tanto em relação à clarificação do efluente quanto ao tempo de resposta após sua adição. Com a flotação por ar dissolvido foi possível reduzir o TOG em até 87,4\% e a DQO até $81,8 \%$.
\end{abstract}

\section{INTRODUÇÃO}

O Brasil possui cerca de 280 mil hectares cultivados com coqueiro, distribuídos, praticamente, em quase todo o território nacional com produção equivalente a dois bilhões de frutos. Embora já estejam devidamente comprovado que são aproveitadas praticamente todas as partes da estrutura do coco, verifica-se que seu processamento industrial gera despejos sólidos, líquidos ou gasosos. Callado e Paula (2009) relatam que numa indústria de processamento de coco os resíduos gerados são casca, aparas, brotos, rejeitos de polpa, coco seco e um grande volume de água de lavagem. Esses despejos não devem ser lançados in natura no meio ambiente (CALLADO, 2009).
Os métodos de tratamento estão diretamente associados ao tipo de efluente gerado, ao controle operacional da indústria e às características da água utilizada. Além disso, o rejeito deve ser descartado de forma que não confira ao corpo receptor características em desacordo com padrões estabelecidos por órgãos ambientais, como o Conselho Nacional do Meio Ambiente (CONAMA 430/11).

\subsection{Coagulação e Floculação}

O processo de coagulação/floculação tem por finalidade a remoção de substâncias coloidais, ou seja, material sólido em suspensão (cor) e/ou dissolvido (turbidez). Essa operação normalmente é considerada como um pré-tratamento que objetiva o 
condicionamento do despejo para o tratamento subsequente (LIMA et al, 2010).

$\mathrm{O}$ controle do $\mathrm{pH}$ é extremamente importante para que ocorra uma boa coagulação e floculação. Dependendo do tipo de coagulante utilizado o $\mathrm{pH}$ pode variar numa faixa muito ampla, o que torna os testes do jarro ("Jar test") indispensáveis para a determinação do $\mathrm{pH}$ ótimo e das dosagens de coagulantes (COUTINHO, 2007).

Para melhorar a floculação e reduzir o consumo de coagulantes primários, têm sido utilizados polímeros sintéticos ou naturais como auxiliares na coagulação, cujas dosagens combinadas devem ser pesquisadas através de ensaios de laboratório realizados com a água ou com o efluente a ser tratado, embora as dosagens de coagulantes devam ser definidas em ensaios de laboratório para cada caso, as suas faixas de aplicação são bastante conhecidas para cada tipo de água ou efluente a ser tratado. (COUTINHO, 2007).

Tabela 1-Principais agentes coagulantes, floculantes, auxiliares de coagulação e floculação

$\begin{array}{cc}\text { Precipitantes Químicos } & \begin{array}{c}\text { Sulfato de alumínio, } \\ \text { Cloreto férrico, Sulfato } \\ \text { ferroso, Sulfato férrico, } \\ \text { Policroleto de alumínio e } \\ \text { Polieletrólitos. } \\ \text { Auxiliares de Floculação } \\ \text { Pcidificantes }\end{array} \\ \begin{array}{c}\text { Polieletrólitos, Sílica } \\ \text { ativada, Bentonita. } \\ \text { Gás carbônico, Ácido } \\ \text { sulfúrico e Ácido } \\ \text { clorídrico. }\end{array} \\ & \begin{array}{c}\text { Cal hidratada, Carbonato } \\ \text { de cálcio, Hidróxido de } \\ \text { sódio e Carbonato de } \\ \text { sódio. }\end{array}\end{array}$

Fonte: Silva (2009)

\subsection{Flotação}

A flotação a ar dissolvido é um processo consagrado em nível mundial para o tratamento de água e de efluentes industriais. Nas últimas décadas, inúmeros pesquisadores realizaram estudos e pesquisas para a utilização da flotação nos mais diversos campos de aplicação, conferindo a esse processo um alto grau de confiabilidade e competitividade com alternativas de separação de sólidos e líquidos e de remoção específica de determinados tipos de poluentes (COUTINHO, 2007).

De acordo com Soletti et al (2006), a flotação é um processo pelo qual há remoção de partículas, líquidas ou sólidas, de uma fase líquida, por meio da introdução de bolhas de gás, as quais aderem à superfície dessas partículas formando aglomerados de densidade menor que a água, que ascendem à superfície, de onde serão removidas.

Para a eficiência do processo de flotação, é fundamental que o contato entre bolha (de ar) e gota (de óleo) seja efetivo, e que as mesmas permaneçam acopladas até que atinjam o topo da célula de flotação. $O$ processo de contato é essencialmente controlado por interações hidrodinâmicas entre as bolhas e as gotas. Em geral, a efetividade do contato ou até mesmo o espalhamento do óleo sobre a bolha dependerá das características superficiais de ambas as fases. (OLIVEIRA et al, 2011).

Nesse trabalho foram estudados três tipos de coagulantes e um polímero aniônico, após diversas analises, o coagulante que mais se destacou entre os três foi utilizado nas corridas experimentais. Foram utilizadas duas configurações de coluna de flotação, e após as corridas experimentais foram realizadas as analises de DQO e TOG, para comparar qual modelo de coluna foi mais eficiente na remoção da DQO e TOG. 


\section{METODOLOGIA}

Inicialmente foram realizadas analises para identificar as melhores condições operacionais relacionada as variáveis objetivando quantificar a dosagem de coagulante e floculante a serem utilizados em cada amostra coletada para seu respectivo $\mathrm{pH}$, bem como o melhor coagulante para $\mathrm{o}$ tratamento. Os experimentos foram realizados em equipamento "jar test", marca POLICONTROL. O efluente analisado foi coletado na indústria de processamento de coco do estado de Alagoas COPRA Alimentícia.

A alimentação do efluente na coluna de flotação foi pela base junto com as microbolhas. O floculante foi injetado em linha a uma quantidade de $20 \mathrm{ppm}$. Os experimentos realizados na coluna de flotação foram realizados em regime estacionário a uma vazão de alimentação do efluente bruto a $80 \mathrm{~L} / \mathrm{h}$ e vazão de diluição de $40 \mathrm{~L} / \mathrm{h}$.

Para o processo de obtenção de microbolhas foi utilizado um vaso de pressão $6 \mathrm{kgf} / \mathrm{cm}^{2}$ (pressão necessária para geração de microbolhas), onde a água e o ar serão confinados e, em seguida, submetidos a uma despressurização através de uma válvula redutora de pressão, surgindo então microbolhas que serão arrastadas pela corrente de água circulante.

As microbolhas entram na coluna flotante onde deverão aderir às partículas de óleos e graxas, ou, na presença de flocos são aprisionadas na estrutura dos mesmos, e levadas até a superfície da fase líquida no topo da coluna. Para determinação do percentual de remoção são coletadas amostras do material antes de sua entrada no processo (alimentação) e após o processo de remoção (base).

A unidade piloto de separação, Figura 1, foi testada em configuração concorrente, sendo constituído, basicamente, de um tanque de alimentação de 150 litros, com agitador mecânico, uma bomba centrífuga; uma bomba de deslocamento positivo para a alimentação da célula de flotação; uma bomba peristáltica para a alimentação da coluna; um turbocompressor, para injeção de ar no equipamento. A unidade foi operada em circuito aberto para não acarretar alteração da concentração do tanque de alimentação.

Figura 1-Esquema da unidade piloto de flotação por ar dissolvido.

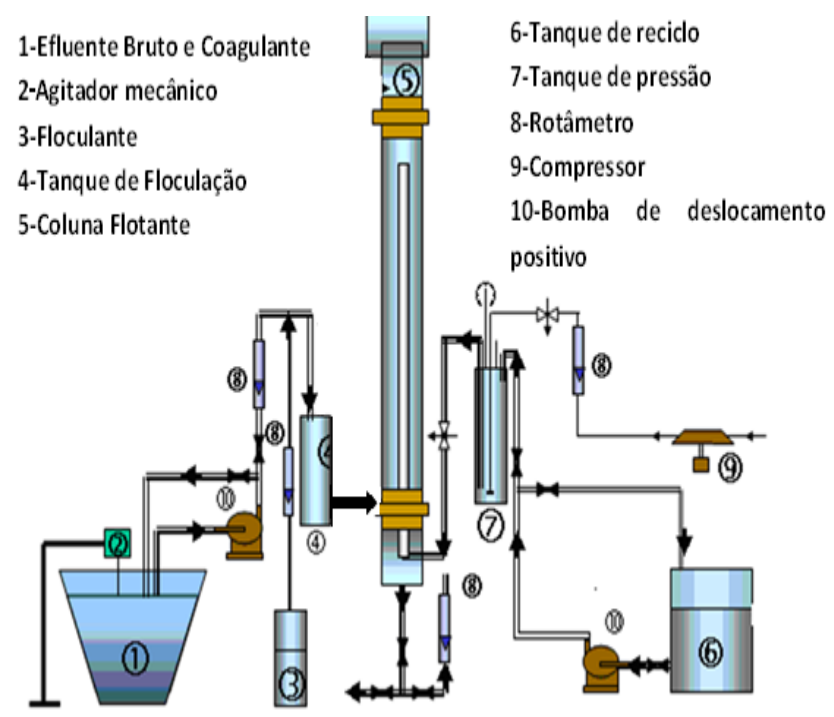

Fonte: SANTOS et al. (2010).

Para análise de TOG inicalmente foram coletados $10 \mathrm{ml}$ de cada amostra. As amostras foram filtradas para retirada dos sólidos contidos no efluente. Em seguida foi adicionado $10 \mathrm{~mL}$ do solvente s-316 em 10 $\mathrm{mL}$ da amostra, após a mistura do solvente com a amostra em um balão de separação, elas formaram fases. A fase contendo $o$ solvente e o óleo foi retirada,e em seguida filtrada com um pouco de sulfato de magnésio, após a filtragem foi realizada a leitura do TOG no equipamento Horiba OCMA-350. 
Para análise da DQO foi utilizado o método de digestão com dicromato. Após a digestão é utilização de um catalisador, sulfato de prata, necessária para tornar possível a oxidação de compostos alifáticos de cadeia reta. Após a oxidação da matéria orgânica presente, a DQO é obtida diretamente $\left(\mathrm{mg} \mathrm{O}_{2} / \mathrm{L}\right)$ no espectrofotômetro DR2000, através de uma curva padrão obtida experimentalmente.

\section{RESULTADOS E DISCUSSÕES}

Inicialmente foram realizados analises de coagulação., e floculação, com 3 tipos de coagulantes, sulfato de alumínio, sulfato de ferro e poli cloreto de alumínio (PAC), Figura 2.

Figura 2-Comparativo entre sulfato de ferro, sulfato de alumínio e PAC.

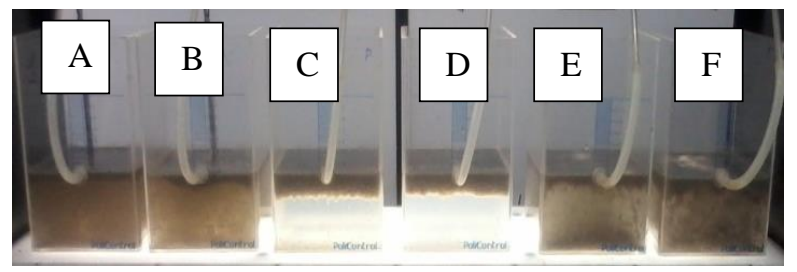

Fonte: Elaborada pelo autor.
A. $\quad 1,5 \mathrm{~mL}$ de sulfato de ferro.
B. $\quad 2,5 \mathrm{~mL}$ de sulfato de ferro.
C. $1 \mathrm{~mL}$ PAC.
D. $2 \mathrm{~mL}$ PAC.
E. $1,5 \mathrm{~mL}$ de sulfato de alumínio.
F. $\quad 2,5 \mathrm{~mL}$ de sulfato de alumínio.

A figura 2 mostra um comparativo entre três coagulantes, sulfato de ferro, policroleto de alumínio (PAC) e sulfato de alumínio. Antes da adição dos coagulantes o efluente bruto tinha $\mathrm{pH}$ 6. Entre os 3 coagulantes utilizados o PAC foi o que obteve melhor resultado, onde as partículas coagularam e flotaram imediatamente após sua adição. Já para os coagulantes sulfato de ferro e de alumínio os efluentes ficaram completamente turvos.

\subsection{Corrida experimental em configuração com tubos concêntricos}

Para coagulação foi utilizado o PAC (poli cloreto de Alumínio), sendo que o efluente apresentava $\mathrm{pH} 6$ e temperatura de $29^{\circ} \mathrm{C}$ antes da adição do polímero e do floculante. No jar test observou-se que o melhor resultado foi obtido com 1,5 mL de PAC para 1 litro de efluente. Foi adicionado ent $165 \mathrm{~mL}$ de PAC no tanque de alimentação. Após sua adição iniciamos a corrida experimental.

A figura 3.b mostra que a coloração do efluente a ser tratado é bem escuro, e que a coluna fica totalmente turva. A grande quantidade de sólidos em suspenção, e gorduras faz com que o efluente tenha essa coloração. É possível observar com o tempo que a base da coluna fica mais clara, mostrando que o óleo está flotando para superfície da coluna, e forma uma espuma no topo.

\subsection{Corrida experimental em configuração com chicanas}

Para essa corrida experimental foi apresentado no jar test, figura 2 , que o melhor resultado da coagulação foi obtido com 2,5 $\mathrm{mL}$ de PAC para $1 \mathrm{~L}$ de efluente. Com base nos resultados, foi utilizado essa mesma proporção para dosar no tanque de alimentação. Foi adicionado ao tanque 363 $\mathrm{mL}$ de PAC, após sua adição iniciou-se a corrida experimental. 
$\mathrm{Na}$ figura 4.b é possível verificar que a coluna com chicanas ficou totalmente turva. Com essa configuração foi observado que grandes quantidades de sólidos ficaram retidas nas chicanas, e em consequência disso, toda a coluna ficou turva.

Com base nos resultados obtidos foi possível comprovar que a flotação é uma grande alternativa para o tratamento de efluentes com elevadas concentrações de TOG e DQO. Através das analises de coagulação e floculação, foi possível observar os diferentes comportamentos do efluente para cada adição de coagulante e assim saber a quantidade ideal a ser utilizada em cada corrida experimental. Também foi possível escolher $o$ coagulante que apresentou melhores resultados dentre os três utilizados. $\mathrm{O}$ policroleto de alumínio (PAC) mostrou desempenho superior aos outros dois utilizados, tanto em relação à clarificação do efluente quanto ao tempo de resposta após sua adição.

A coluna com tubos concêntricos foi a que apresentou melhores resultados. Foi observado que esses resultados podem ser melhorados, com algumas alterações no flotador, no intuito de aumentar o tempo de residência das microbolhas com o óleo, e melhorar a recirculação das microbolhas dentro da coluna.

Após as corridas experimentais realizadas no flotador comparamos todos os resultados para a remoção do TOG e DQO conforme mostra a tabela3.
Figura 3- Experimento realizado na coluna com tubos concêntricos, antes e durante operação.

$\begin{array}{ll}\text { a) Antes do inicio da } & \text { b) } 75 \text { minutos após o inicio }\end{array}$ corrida experimental da corrida experimental
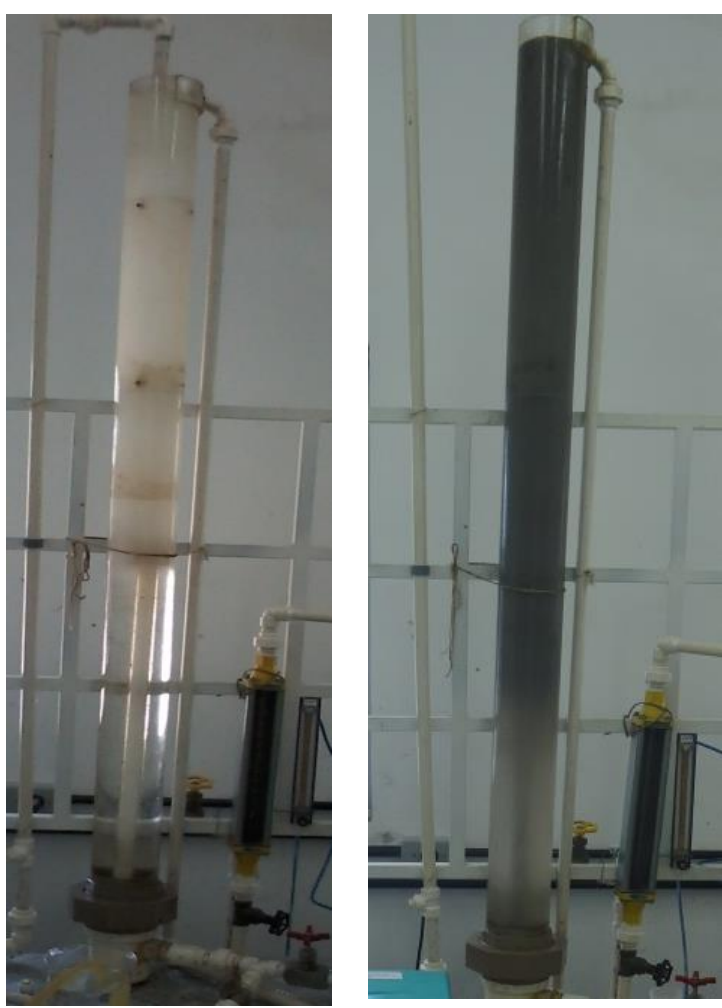

Fonte: Elaborada pelo autor.

Tabela 3- Comparativo entre as remoções de TOG e DQO dos experimentos realizados na coluna com tubos concêntricos e com chicanas.

\begin{tabular}{ccccc}
\hline & \multicolumn{2}{c}{$\begin{array}{c}\text { Experimento 1 } \\
\text { (tubos }\end{array}$} & \multicolumn{2}{c}{$\begin{array}{c}\text { Experimento 2 } \\
\text { (chicanas) }\end{array}$} \\
& \multicolumn{2}{c}{ concêntricos) } & & \\
& TOG & DQO & TOG & DQO \\
& $(\boldsymbol{\%})$ & $(\boldsymbol{\%})$ & $(\boldsymbol{\%})$ & $(\boldsymbol{\%})$ \\
Coleta 1 & 59,4 & 68,75 & 76,8 & 49,7 \\
Coleta 2 & 87,4 & 81,75 & 83,5 & 58,87 \\
\hline
\end{tabular}


Figura 4- Experimento realizado na coluna com chicanas, antes e durante operação.

a) Antes do inicio da corrida experimental

b) 75 minutos após o inicio da corrida experimental

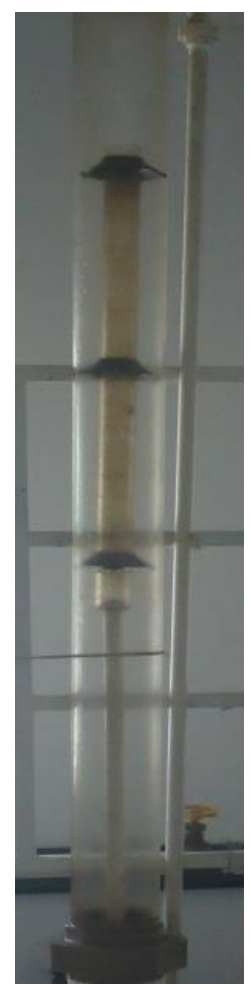

Fonte: Elaborada pelo autor.

Fonte: Elaborada pelo autor.

Pode-se dizer que a flotação é uma grande opção para o tratamento de efluentes da indústria do coco, visto que esse efluente apresentavam altos valores: de TOG e DQO, $189 \mathrm{ppm}$ e $7041 \mathrm{mg} \mathrm{O}_{2} / 1$ respectivamente e que foi possível baixar esses valores para até $24 \mathrm{ppm}$ de TOG e redução da DQO para $608,3 \mathrm{mgO}_{2} / \mathrm{L}$.

Esses valores mostram que para a remoção do TOG esse efluente se enquadrou nos padrões para descarte estabelecidos pala (CONAMA 430/2011), em relação a DQO os valores ainda estão um pouco altos e fora dos padrões para descarte, porem vale destacar que a DQO foi reduzida em $81,75 \%$, o que mostra uma alta porcentagem de remoção da matéria orgânica presente no efluente.

\section{CONCLUSÕES}

Com base nos resultados obtidos podese dizer que a flotação é uma grande alternativa para o tratamento de efluentes da indústria do coco, visto que esse efluente apresentava altos valores de TOG e DQO, sendo possível remover até 87,4 do teor de óleo graxo (TOG) e $81,75 \%$ da demanda química de oxigênio (DQO). Os resultados obtidos foram promissores no aspecto de remoção do TOG e DQO, e a coluna com configuração com tubos concêntricos foi a que apresentou resultados melhores.

Os estudos de coagulação e floculação foram fundamentais para saber a quantidade ideal a ser utilizada em cada corrida experimental. Foi observado que o poli cloreto de alumínio foi o que mais se destacou, necessitando de uma forma geral de pequenas quantidades para que fossem obtidos resultados satisfatórios, com tempo de resposta imediato após sua adição.

\section{REFERÊNCIAS}

CALLADO, N. H.; PAULA, D.R. Gerenciamento de resíduos de uma indústria de processamento de coco. In: CONGRESSO BRASILEIRO DE ENGENHARIA SANITÁRIA E AMBIENTAL, 20; 2009. Rio de Janeiro, Rio de Janeiro. Anais... Rio de Janeiro, Rio de Janeiro. 2009. 10p.

CONAMA 430/11, 2011, Resolução do Conselho Nacional do Meio Ambiente, CONAMA No 430.

COUTINHO,W. .Docentes UFMG: emprego da flotação a ar dissolvido no tratamento de cursos d'água, 2007. Dissertação 
(Mestrado em Recursos Hídricos)Universidade Federal de Minas Gerais, Belo Horizonte, MG, 2007.

LIMA,V.L.G ; FAGUNDES ， K.,M.R; VEIT, M.T; SILVA, E.A; BARBIERO, T.A; BERGAMASCO, R.. Avaliação da eficiência de diferentes agentes coagulantes na remoção de cor e turbidez em efluente de galvanoplastia, Eclet. Quím. vol.35 no.4 São Paulo 2010.

OLIVEIRA JUNIOR, A. M.; JESUS NASCIMENTO, A. G. ; SILVA SANTOS, T. C.; ANDRADE, S. F. ;SANTOS, E. J. ; MARQUES, J. J. Uso de reator air-lift em batelada para tratamento de efluentes de uma indústria de beneficiamento de coco. Exacta.vol 9. Num 2. São Paulo. 2011.

SOLETTI, J. I ;SILVA, D. I. S. ; SILVA, S. R.; TONHOLO, J; ZANTA C. L. P.
Tratamento de efluente da indústria de laticínios através de flotadores e processos eletroquímicos. In: CONGRESSO BRASILEIRO DE ENGENHARIA QUÍMICA, 16, Santos, São Paulo. Anais... 2006. 6p.

SILVA, Sandra Rodrigues. Tratamento de efluentes de indústria de beneficiamento de coco. 2009. 92 p. Dissertação (Mestrado em Engenharia Química). Universidade Federal de Alagoas, Maceió, Alagoas.

\section{AGRADECIMENTOS}

Ao $\mathrm{CNPq}$, pelo apoio financeiro concedido para a realização do estudo, ao professor João Inácio Soletti por suas orientações, e aos integrantes do Lassop (laboratório de sistemas de separação e otimização de processos). 